\title{
Mobile Based Agriculture and Climate Services Impact on Farming Households in Rural Kenya
}

\author{
Lilian Muasa $^{1} \&$ Hirotaka Matsuda ${ }^{2}$ \\ ${ }^{1}$ Graduate Program in Sustainability Science-Global Leadership Initiative, The University of Tokyo, Japan \\ 2 Department of Agricultural Innovation for Sustainability Faculty of Agriculture, Tokyo University of \\ Agriculture, Japan \\ Correspondence: Lilian Muasa, Graduate Program in Sustainability Science-Global Leadership Initiative, The \\ University of Tokyo, Japan. E-mail: lillianmuasa02@gmail.com; muasa@s.k.u-tokyo.ac.jp
}

Received: November 29, 2018

Accepted: January 12, 2019

Online Published: March 30, 2019

doi:10.5539/jsd.v12n2p1

URL: https://doi.org/10.5539/jsd.v12n2p1

\begin{abstract}
Rural farming households in semi-arid regions in Kenya are vulnerable to climate change impacts due to overreliance on rain fed agriculture and low adaptive capacity. Farming households' adaptive capacity development is detrimental to enable them cope with short and long term impacts. Information Communication and Technology (ICTS) play an essential role in adaptive capacity development by ensuring access to information and knowledge related to agriculture and climate. The mobile phone is one of dominant ICT tool with wider ownership and promising technology for information accessibility. The increasing mobile penetration rate in Kenya has initiated the development of a wide range of agricultural related mobile phone services and applications targeting rural households to increase their agricultural productivity and strengthen their adaptive capacity in the face of climate change. This study examines households use and benefit from the developed mobile phone services and applications to access information related to agriculture and climate change. Using data of 120 households' multinomial probit analysis is applied to identify factors that determine the adoption of the mobile phone. Findings reveled that through developed mobile phone services and applications, Kenyan rural households are able to access; mobile money banking, extension services, obtain credit, agriculture information, weather information and market information. Access to these services increases household capacity and reduce information asymmetry. Feature phone and smart phones are the types of mobile phone used across households. Multinomial probit analysis elicits that probability of feature phone adoption increases with a decrease in household income while that of smart phone increases on male headed households, increases with an increase in household income and accessibility to credit.
\end{abstract}

Keywords: mobile phone, rural, household, agriculture, climate change, adaptive capacity, Kenya

\section{Introduction}

The mobile phone is a dominant force in Information, Communication and Technologies (ICT) due to its affordability and wide ownership. In many developing countries the mobile phone uptake has significantly impacted economic initiatives which have initiated governments, private corporations and Non-governmental organizations in explaining the possibilities and imperativeness of using a mobile phone to communicate with citizens (Crandall, 2012). According to International Technology Unions (ITU) report in 2017 the world mobile phone subscriptions are more than the people. Furthermore, ITU indicates that the mobile phone adoption in developing countries has increased from $96.3 \%$ in 2016 to $98.7 \%$ by the end of 2017 (ITU,2017).

The mobile phone has been depicted to have a greater impact on agricultural development through information accessibility, increase in agricultural extension outreach and financial accessibility though voice calls, SMS and mobile based applications (Lawal et al, 2010; Qiang, 2015; COP 21, 2015). Mittal et al pointed out that mobile phone is not being used to its full potential while mobile phones are currently being used in ways that contribute to farm productivity, and thus farmers' capacity to use the provided services need to be improved (Mittal et al 2012, Aker, 2016).In Kenya, which is one of leading countries in sub-Sahara Africa and a case country of this study, the mobile phone penetration rate has been skyrocketing from $76.8 \%$ in 2012 to $88.6 \%$ in 2018 and it is projected to increase to $96.3 \%$ by 2020 (Communication Commission of Kenya, 2018). This high mobile phone penetration rate indicates that mobile phone technology is a promising business opportunity as well as an 
indispensable tool for empowering the population especially in rural areas. Majority of Kenya population (78.4\%) live in rural areas and they largely rely on rain fed agriculture for livelihood (FAOSTAT, 2010; KNBS, 2009). Farmers in a rural area of Kenya are vulnerable to various types of risks including current anomaly weather event and projected climate change in the future. Due to climate fluctuations and weather extremes which are expected to suffer disproportionality from climate change, the rural population is more vulnerable (CGIAR, 2018) and access to both agricultural and climate information offer great potential to enable farmers to make informed decisions, take advantage of favorable climate conditions and adapt to change. Currently in Kenya, a wide range of mobile phone initiatives using voice calls, SMS and applications have been developed to provide information and financial services to rural farmers. It is expected that the mobile phone may play a role to mitigate the vulnerability of farmers in rural Kenya. Therefore, this study seeks to better understand the role of the mobile phone to access services by rural Kenya farmers in order to enhance agricultural development in the face of changing the climate. Furthermore, this study identifies factors that determine the adoption of the mobile phone.

The developed agricultural based services in Kenya are based on voice calls, SMS and installed applications. The information provided is based on three themes; agricultural information, climate/weather information and market information. Some of these information providers include; Kenya Agricultural Commodity Exchange (KACE) a voice calling and SMS based information service in which the farmers can receive Market information in Kenya (KACE, 2018), MFarm Ltd an SMS based service which provides access to localized, current data on market and weather information (MFarm Kenya, 2018) and I-cow an SMS based service which provides dairy cow information. Some of the financial based services are; M-Pesa (Mobile money) a SMS based service which helps farmers receive and send money through the mobile phone (M-Pesa Kenya, 2018), M-Shwari a SMS based service in which the farmers can be able to access short term loans (M-Shwari Kenya, 2018) and M-Farmer initiated fund by GMSA which provides smallholder farmers with financial advisory services in developing countries (GSMA, 2011).

It is imperative to understand how the rural farmers are using mobile phones and a wide range of developed services and applications in order to ensure that the developed initiatives precisely address farmer's concerns to improve their agricultural productivity in the face of climate change. This paper entails; mobile penetration rate and usage patterns of the mobile phone in Makueni County, how the farming households use the developed services to access information and financial services, the barriers to use and accessing information and financial services provided and factors that determine adoption of the mobile phone.

\section{Materials and Method}

\subsection{Study Area}

This study employs a reality check in Makueni County an arid and semi-arid region located in the Eastern part of Kenya. It has a total population of 884,527 people and covers an area of $8,035 \mathrm{~km}$ comprising of $594 \mathrm{~km} 2 \mathrm{urban}$ areas and around $7441 \mathrm{~km} 2$ rural areas for agriculture and other activities (KNBS, 2010). Figure 1 shows the location of Makueni County in the map of Africa and Kenya.

Agriculture is a predominant economic activity and employs the highest number of Makueni county residents with around $87.1 \%$ relying on it for livelihood. These are evident by $78.0 \%$ out of 120 interviewed respondents in this study relying dominantly on farming. The monthly income of a household is estimated at 370 dollars a month. Makueni County experiences cyclical droughts that have become severe and frequent resulting in total crop failure (Bukania et al, 2014) 


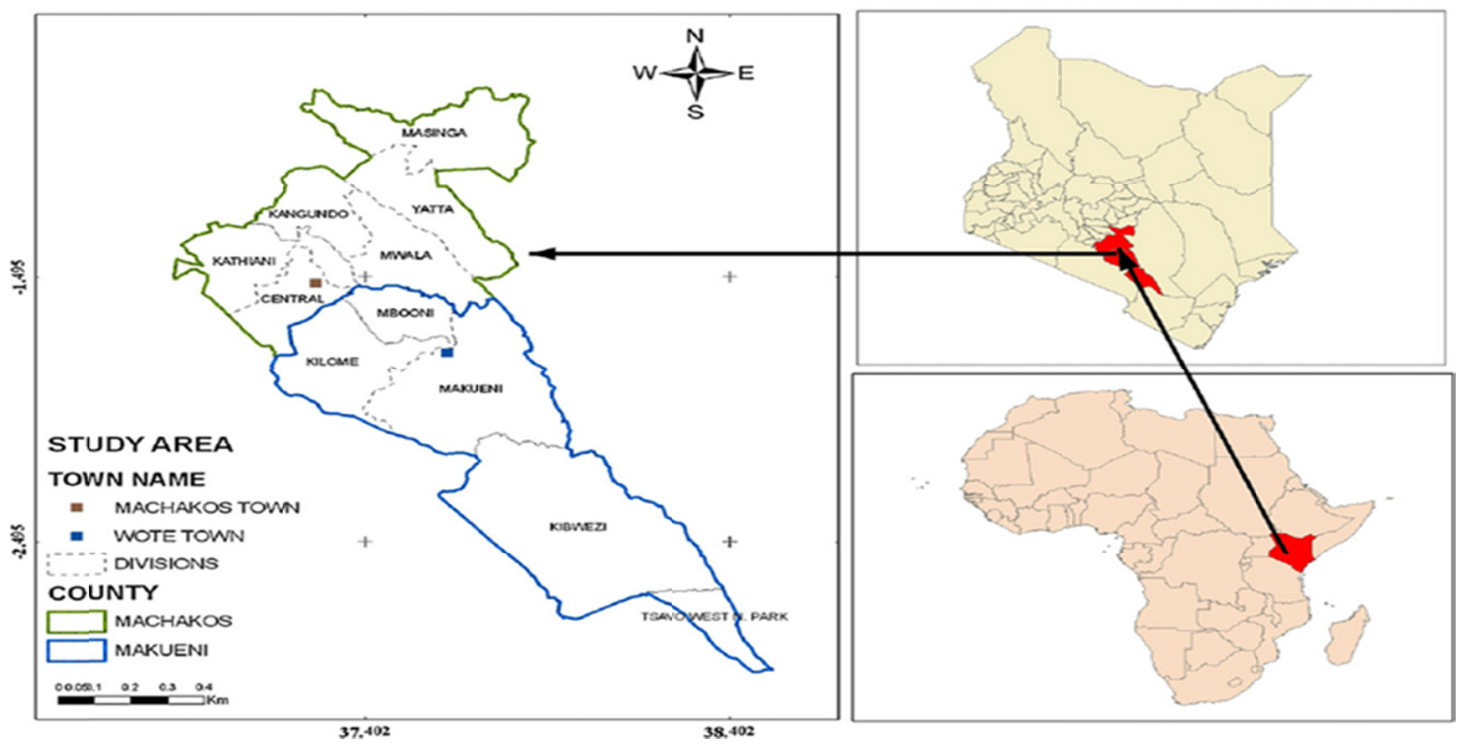

Figure 1. Map of Makueni County (KNBS, 2010)

\subsection{Data Collection and Analysis}

This study employs both qualitative and quantitative methods. In data collection, the triangulation method is applied by using a household questionnaire, key expert interviews and focus group Discussions. A meticulous semi-structured questionnaire administration was conducted across randomly sampled households that yielded 120 questionnaires. The household questionnaire comprised of both open-ended and closed ended questions and was designed to comprise of four sections which captured data on; household socio-demographic characteristics, mobile phone usage information, use of mobile phone on agriculture and climate change adaptation information, use of mobile phone for financial and diversity of livelihood. It also captured challenges or barriers that the mobile phone users experience to access agriculture based and climate change adaptation services. Relevant to climate change collection was included in the questionnaire as a case of facing vulnerability of farmers in order to capture the contributions of the mobile phone to mitigate the vulnerability of farmers. The household questionnaire targeted the household head or the spouse. The interviewed households comprised of $38.0 \%$ male and $62.0 \%$ female with the majority being above 35 years of age. Furthermore, 7 key expert interviews and 6 focus group discussions were conducted to provide more qualitative data regarding mobile phone usage and application on agriculture and climate change adaptation.

The collected data is descriptively analyzed and we applied multinomial probit model (Cameron et al., 2009; Alvarez et al., 1994; Cameron et al., 2005) to estimate the impact of different factors on the choice of mobile phone used by the household.

$$
\begin{gathered}
y_{i}=j, \quad \text { if } \max _{j=0, \ldots ., p} y_{i j,}^{*}, \\
y_{i j}^{*}=x_{i j}^{\prime} \beta+u_{i j}, \quad j=1, \ldots \ldots p, \\
u_{i j} \sim N(0, \Sigma)
\end{gathered}
$$

It is assumed that there are $p+1$ alternatives. $y_{i}(i=1, \ldots, n)$ is the result of choice and indicated in an integer from 0 to $p . X_{i}=\left(\mathrm{x}_{\mathrm{i} 1}, \ldots, \mathrm{x}_{\mathrm{ip}}\right)$ is a vector of factors for choices. $x_{i j}(j=1, \ldots ., p)$ is k-dimensional vector for choice $j . y_{i j}^{*}$ is an unobserved evaluation for alternatives and normalized at $y_{i j}^{*}=0$. In this study, households have three choices, no mobile phone, feature phone and smart phone. Alternatives of the mobile phone are considered: no mobile phone $(=0)$, feature phone $(=1)$ and smart phone $(=2)$. Considering factors for mobile phone adaptation are household income, household head age, educational level of the household head, and gender of household head, access to credit, cultivated land size and participation on farming training. $\beta$ is the coefficient of estimation. $u_{i}=$ 
$\left(u_{i 1}, \ldots, u_{i p}\right)^{\prime}$ is error term, a p-variate normal distribution with mean 0 and variance covariance matrix $\Sigma$. Furthermore, the marginal effects of explanatory variables which are statistically significant different from 0 are estimated to provide insights into how they shift the likelihood of the frequency of mobile phone adoption across households. Table 1 indicates the definition of variables and their mean values.

Table 1. Definition of variables

\begin{tabular}{llll}
\hline Variables & Definition & $\begin{array}{l}\text { The frequency of household } \\
\text { in } \%\end{array}$ & Mean \\
\hline Feature phone & Own $(1=$ Yes, $0=\mathrm{No})$ & Yes $=57.5$ & - \\
Smartphone & Own $(1=$ Yes, $0=\mathrm{No})$ & Yes $=35.8$ & - \\
Age & Number of years of household head & - & 48 years \\
Education & Numbers of years of schooling of household head & - & 11 years \\
Gender & Gender of household head $(1=$ Male, $0=$ Female $)$ & Male $=38.0$ & - \\
& & Female $=62.0$ & $36.95 \$$ \\
Per-HH Income & Monthly household income & - & 2.1 ha \\
Per-Land & Land size per household member $($ ha $)$ & - & - \\
Credit Acc & 1= Access, $0=$ Don't access & Access $=50.8$ & Don't access $=49.2$ \\
& & Yes $=24.2$ & - \\
\hline
\end{tabular}

\section{Results and Discussions}

\subsection{Descriptive Analysis of Mobile Phone Usage}

Out of 120 interviewed households, $94.0 \%$ own a mobile phone and $6.0 \%$ without mobile phone stated that they are not able to afford and others don't know how to operate it. Feature phone (second generation phones) is the commonly used kind of mobile phone across households (57.5\%), with $35.8 \%$ being smart phone users. Although the majority use feature phones, mobile phone proved to be a basic asset used by households to access services by household since the mobile phone usage period was above 5 years. Safaricom one of the largest mobile network service provider in Kenya is the dominantly used network by many households $(90.0 \%)$ with the other service providers (Airtel, Orange and Yu) taking only 10.0\%. Other than service provision, Safaricom provides a wide range of accessible mobile phone applications to its subscribers, developed to enhance rural development for instance, mobile money transfers services (M-Pesa), credit services (M-Shwari), M-Kopa) and agricultural based applications (M-Farm, Kenya agricultural commodity exchange (KACE), Soko Hewani, I-Cow, M-Kilimo, Arifu-Mkulima)).

Figure 2 shows the common purposes of mobile phone applied by the majority of households in Makueni County. Other than communication (97.5\%) which is the dominant purpose, other purposes include money transfer services (74.2\%), social networking (53.0\%), obtain credit (30.0\%) and also access extension services (29.0\%). 


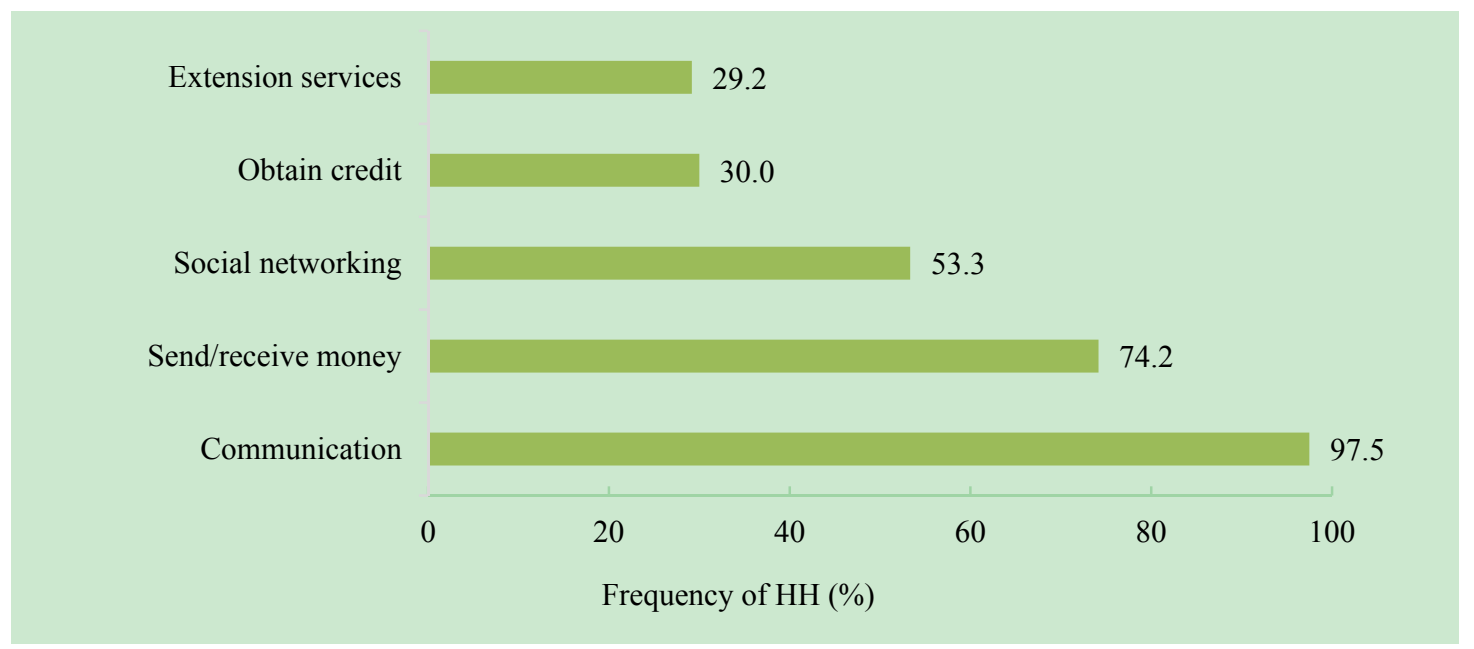

Figure 2. Purposes of mobile phone across farming households (Source: Authors)

\subsection{Household Mobile Phone Usage on Accessing Information and Financial Services}

The uses of the mobile phone by households on this study is assessed based on the following themes: access to agriculture information, seeking agriculture emergency assistance, accessing financial services and coordinating and monitoring of household livelihood activities.

In this study, only $34.0 \%$ out of 120 interviewed households use a mobile phone to access agriculture information. They access this information through voice calling $(58.0 \%)$, text messaging $(26.0 \%)$ and through the internet $(14.0 \%)$. Most of the households use a mobile phone to contact extension officers $(45.0 \%)$, fellow farmers $(38.0 \%)$ and friends $(15.0 \%)$ to access the agriculture, market and climate information through voice calling and text messaging. The agricultural information the households seek is most on crop and livestock (75.0\%), crops only (12.0\%) and livestock only $(51.0 \%)$. The kind of agricultural information received includes, pest and diseases, crop varieties and artificial insemination (AI) regarding crop and livestock. Also, some households $(45 \%)$ receive downscaled climate information through text messages from the Kenya Meteorological Department (KMD). Majority of households (66.0\%) lack access to agriculture and climate information despite many developed mobile phone applications and uses targeting rural households in Kenya.

A mobile phone also plays a role in accessing financial services across households since the majority (91.0\%) receive remittances through their mobile phone from family and friends. A mobile phone application 'M-Pesa', developed in 2007 by Safaricom, one of the dominant network service provider in Kenya is widely used by the households to receive and send money through their mobile phone. The M-Pesa application is widely accessible and any kind of mobile phone either a smart phone or feature phone can be used so long as it has network coverage and the user is legally registered. Also, the majority of the interviewed households are able to access credit through their mobile phone (81.0\%). An application developed by Safaricom called 'M-Shwari' enhanced accessibility to credits to small holder farmers. Majority of the rural poor farmers are not banked and therefore these services grant them an opportunity to access these services without many formalities required by the ban to access credit. This study further investigated whether the household uses the money received through their mobile phone for farming activities. The majority $(61.0 \%)$ indicated that they use the money for farming activities as indicated in figure 3; 


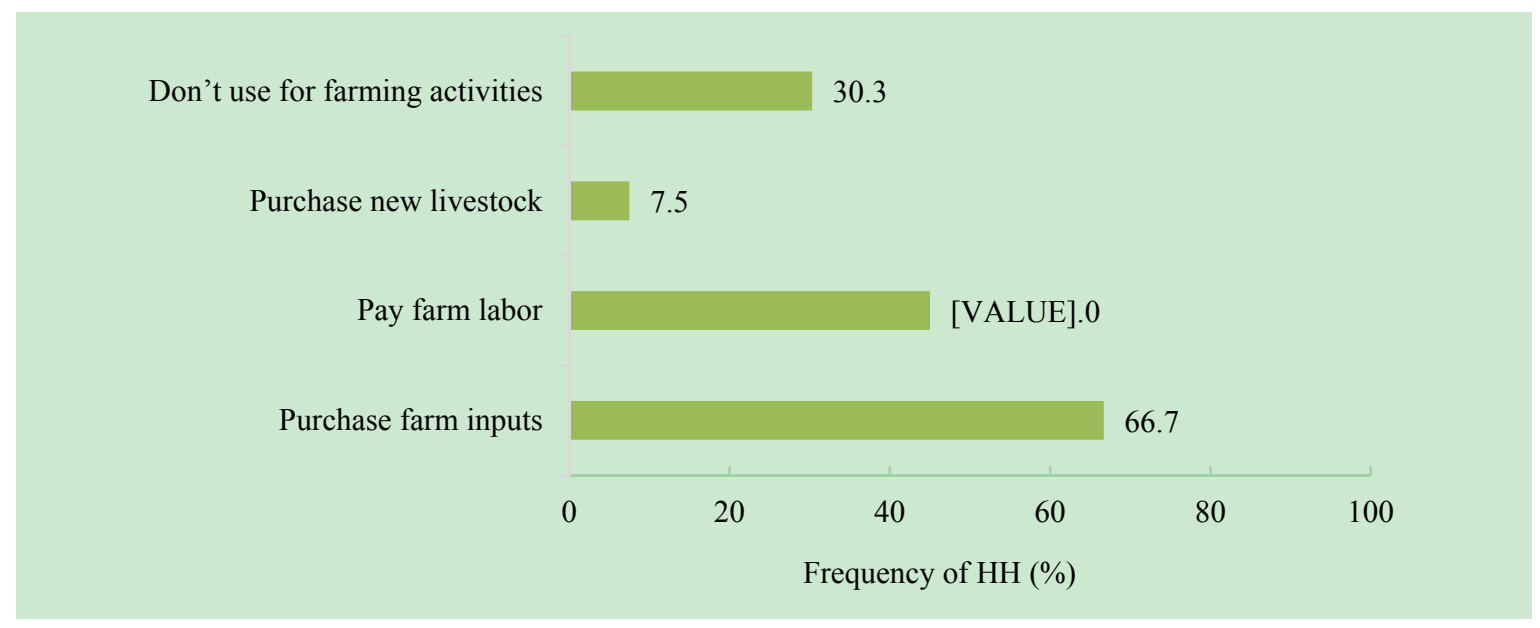

Figure 3. Uses of mobile money by households in farming activities (Source: Authors)

As indicated in figure 3, apart from other basic uses of mobile money, households use the received money for farming activities; to purchase farm inputs $(62.0 \%)$, pay farm laborers $(41.0 \%)$ and purchase new livestock (9.0\%). Only $39.0 \%$ out of 120 interviewed households use the received money for other household purposes and not farming activities.

Although farming is the main livelihood activity among the interviewed households in Makueni County, the majority $(58.0 \%)$ engage in other activities in order to diversify their household income. As indicated in figure 4, these activities include; small businesses (10.0\%), causal jobs (wages 18.0\%) and others have permanent jobs (Salary $20.0 \%$ )

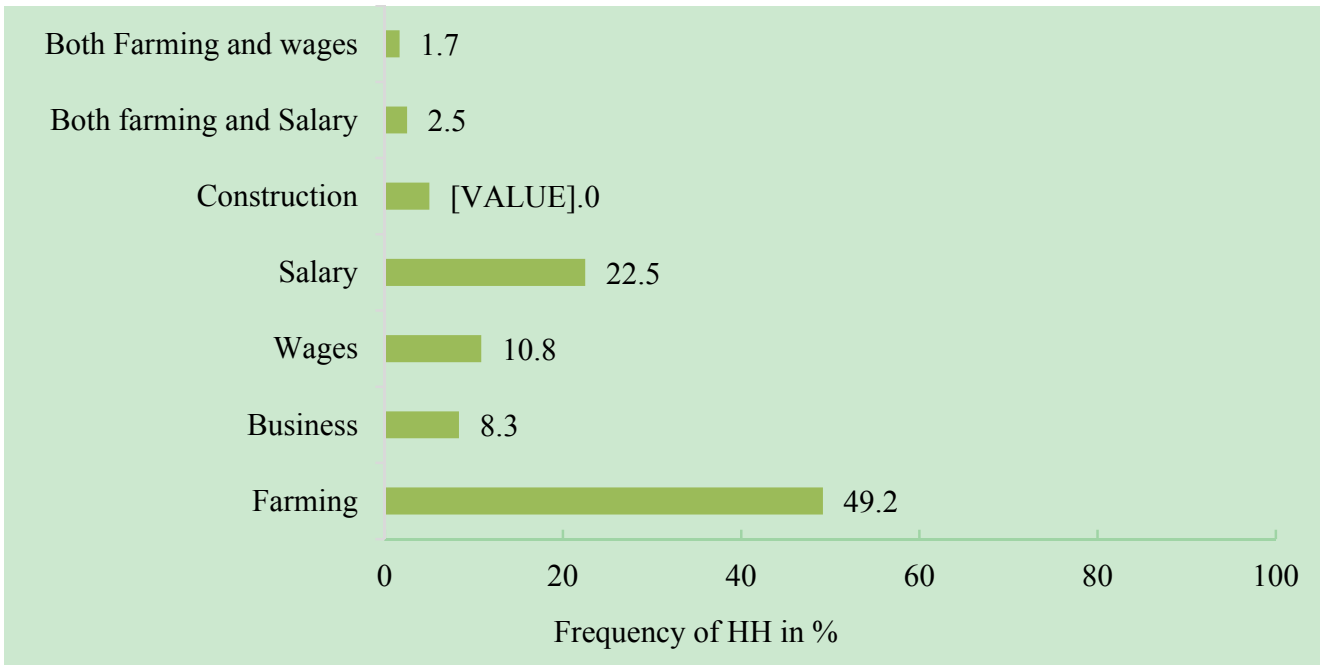

Figure 4. Sources of household income

Furthermore, this study investigated how the household is able to manage all the livelihood activities together and whether the mobile phone plays a role in enhancing operation, management and monitoring of the activities. The households indicated that they get support from family members (51.0\%), from employees $(14.0 \%)$ and others get support from both family and employees $(17.5 \%)$ to manage and operate the different livelihood activities they engage in. Also, the study depicts that $51 \%$ of households use a mobile phone to operate, monitor and manage the different livelihood activities through voice calling $(51.0 \%)$, text messaging $(3.0 \%)$ and others use both calling and text messaging (46.0\%). The interviewed households revealed that the use of mobile phone is beneficial to their farming activities. Table 1 shows a summary of the benefits of the mobile phone on household farming activities. 
Table 2. Benefits of the mobile phone on household farming activities

\begin{tabular}{lc}
\hline Benefit & The frequency of households \\
& in \% \\
\hline Timely acquisition of price, market and farming practice information & 75.0 \\
Facilitates access to technical and financial services & 72.0 \\
Easy connect with other farmers for more effective collective action & 64.0 \\
Reduced cost of doing things & 75.0 \\
Reduced travel hours & 72.0 \\
Increased social networks & 66.0 \\
Easier to link my products to distant markets and higher and agricultural value & 46.0 \\
chains & 54.0 \\
Get advance warning of weather risks & \\
\hline
\end{tabular}

As indicated in table 2, the mobile phone is an essential tool and it enhances the household's access to agricultural information, finances and diversification of livelihood. Accessibility to these resources strengthens the household mitigation capacity of vulnerability including the adoptive capacity to climate change. The households are able to identify which adaptive strategies they are able to apply to counteract the weather changes the farmers receive.

\subsection{Challenges Experienced by Households to Access Agricultural Based Mobile Phone Services}

Although the farmers indicated that the use of mobile phone has benefited them in farming activities, they have been experiencing challenges in accessing information and financial services illustrated in figure 5 .

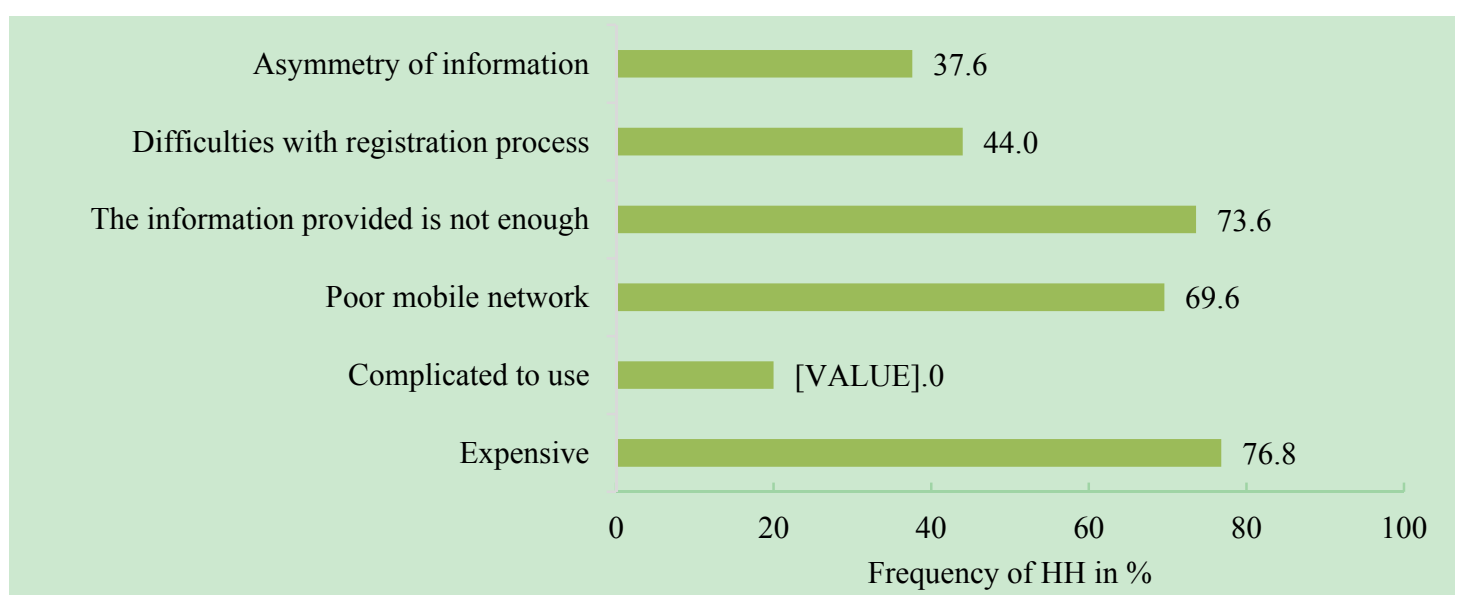

Figure 5. Challenges experienced by households to access agricultural based mobile phone services (Source:

Authors)

As indicated in figure 5, most of the households stated that accessing the agricultural based information services are expensive (76.5\%) since the households have to pay for the calls and text messages. These text messages are charged more than the normal text messages which limit the households from frequently using the services. Also, the households indicated that the information provided is not enough (73.6\%), it only covers a few crops and also does not provide all the information the farming households seek. Another challenge the households experience is that the mobile network coverage is poor sometimes which hinder accessing the information through the mobile phone. Other challenges the households experience include; registration process to access the information is difficult (44.0\%) and there is information asymmetry $(37.6 \%)$ more so the market information, sometimes the information delay creating a difference with the current price or quality in the market.

\subsection{Factors That Determine Mobile Phone Adoption by Households}

In the diffusion theory of technology (Rogers, 2003; Murray, 2009), it explains why coordinating access to 
agricultural inputs is the most frequently cited agricultural-based mobile phone use. One of the main arguments of diffusion theory of technology is that individuals are more likely to adopt an innovation if it provides a relative advantage over current practice and especially if the individual can see others gaining advantage from adoption (Rogers, 2003; Murray, 2009). This study links to this theory by assessing the factors that make the households likely to adopt a mobile phone in rural Kenya based on the idea that the mobile phone has been beneficial to them. In addition, the majority of the respondents has adopted mobile phone (94.0\%) and has owned it for more than 5 years.

In this study, a multinomial probit model was hired to predict proximity of adopting a certain type of mobile phone either a feature phone or smartphone from the following selected independent variables; Household income, the age of the household head, education, participation in farmers' organization and household access to credit.

Table 3 shows the estimated results of the multinomial probit model on the effect of various factors that determine the adoption of feature phone and smart phone. The base of estimation is no mobile phone case. As in indicated in the previous section, almost all the household $(94.0 \%)$ have a mobile phone. However selected factors to explain the adoption of the mobile phone are different among types of the owned mobile phone when sample house households are categorized by types of owned mobile phone, feature phone and smart phone. Most of the factors are not statistically significantly different from 0 for a feature phone. Because almost all the household can have a feature phone at affordable cost, factors to differentiate the probability of having a feature phone among the households cannot be found. An interesting estimation result is per-household member's monthly income, Per-HH Income. The estimated parameter is statistically significantly different from 0 but the sign is negative. It is indicated that increasing per-household member's income moves them to switch to a smartphone. The parameter of Per-HH Income in smartphone case is statistically significantly different from 0 and sign of it is positive. In case of estimation results of a smart phone, a parameter of land size per household member, Per-Land, accessibility to credit, Credit ACC, and male of household head, gender, are statistically significantly different from 0 . Sign of them is of negative, positive and positive, respectively. It is usually expected that land size per household member is positive because income from farming is higher with larger cultivated land. The most plausible explanation of this is that smart phone holder has other sources of income other than farming. In other words, regular farmers do not have a strong motivation to obtain a smartphone.

The status of agricultural production among samples is not so different. Because of the situation, an estimated parameter of land size per household member, which is one of the indicators of regular farmers, is statistically significantly different from 0 with a negative sign. Accessibility to credit enhances the household to purchase a smart phone as consumption or an investment good. From both perspectives, an estimated parameter of credit accessibility, Credit $A C C$, is statistically significantly different from 0 with a positive sign. Finally, it is indicated that the likelihood of having a smart phone by the male head household head is larger. This implies that the resource allocation of the household is affected by the intention of male since he is the main household provider. In addition, most of the women. The three alternatives were applicable in all the age groups of households as well as the gender of the household. Majority of the household head has an education above primary school level thus the ability to operate a mobile phone was common and does not influence the type of mobile phone being adopted by the household. The training is more focused on agricultural based activities and information on the importance of using a mobile phone is not involved in the program. 
Table 3. Estimates of the multinomial probit model

\begin{tabular}{ccc}
\hline & Feature Phone & Smart Phone \\
\hline Cons & $3.280^{* *}$ & 0.675 \\
& $(2.28)$ & $(-0.40)$ \\
Age & $-0.35^{*}$ & 0.002 \\
& $(-1.69)$ & $(0.09)$ \\
Education & 0.45 & 0.009 \\
& $(0.30)$ & $(0.05)$ \\
Gender & 0.617 & $1.551^{*}$ \\
& $(0.90)$ & $(1.86)$ \\
Per-HH Income & $-0.000^{*}$ & $0.000^{* * *}$ \\
& $(-1.77)$ & $(2.62)$ \\
Per-Land & -0.375 & $-1.769^{* * *}$ \\
& $(-0.87)$ & $(-2.78)$ \\
Credit Acc & 1.402 & $3.094^{* * *}$ \\
& $(1.43)$ & $(2.97)$ \\
Train & -0.825 & -0.798 \\
& $(-1.05)$ & $(-0.94)$ \\
\hline Total Observations & & \\
\hline Log likelihood & & $-71.609^{* * *}$ \\
\hline
\end{tabular}

Note 1: Three choices, No mobile phone, Feature phone and Smart phone, are used for estimation. No mobile phone is used as a base of estimation.

2: Z-score is indicated in parentheses. ${ }^{* * *}, * *, *$ are indicated statistical significantly different from 0 at $1 \%$, $5 \%$ and $10 \%$ level respectively.

Table 4 indicates the estimated marginal effect of three variables which are statistically significantly different from 0 in the smart phone case, Per-HH Income, Per-Land and Acc Credit. Although those are not always statistically significantly different from 0 in cases of No mobile phone and Feature phone, those are indicated in the table to compare. In addition, Figure $6 \mathrm{a}$ and $6 \mathrm{~b}$ show a variation of prediction probability of smart phone by Per-HH Income and Per-Land obtained from marginal effect in table 4.

Table 4. Marginal effect of selected variables

\begin{tabular}{crrr}
\hline & Per-HH Income & \multicolumn{1}{l}{ Per-Land } & \multicolumn{1}{l}{ Credit Acc } \\
\hline No Mobile Phone & 0.00000 & 0.04787 & -0.10389 \\
Feature Phone & -0.00024 & 0.34951 & -0.39873 \\
Smart Phone & 0.00024 & -0.39738 & 0.50262 \\
\hline
\end{tabular}




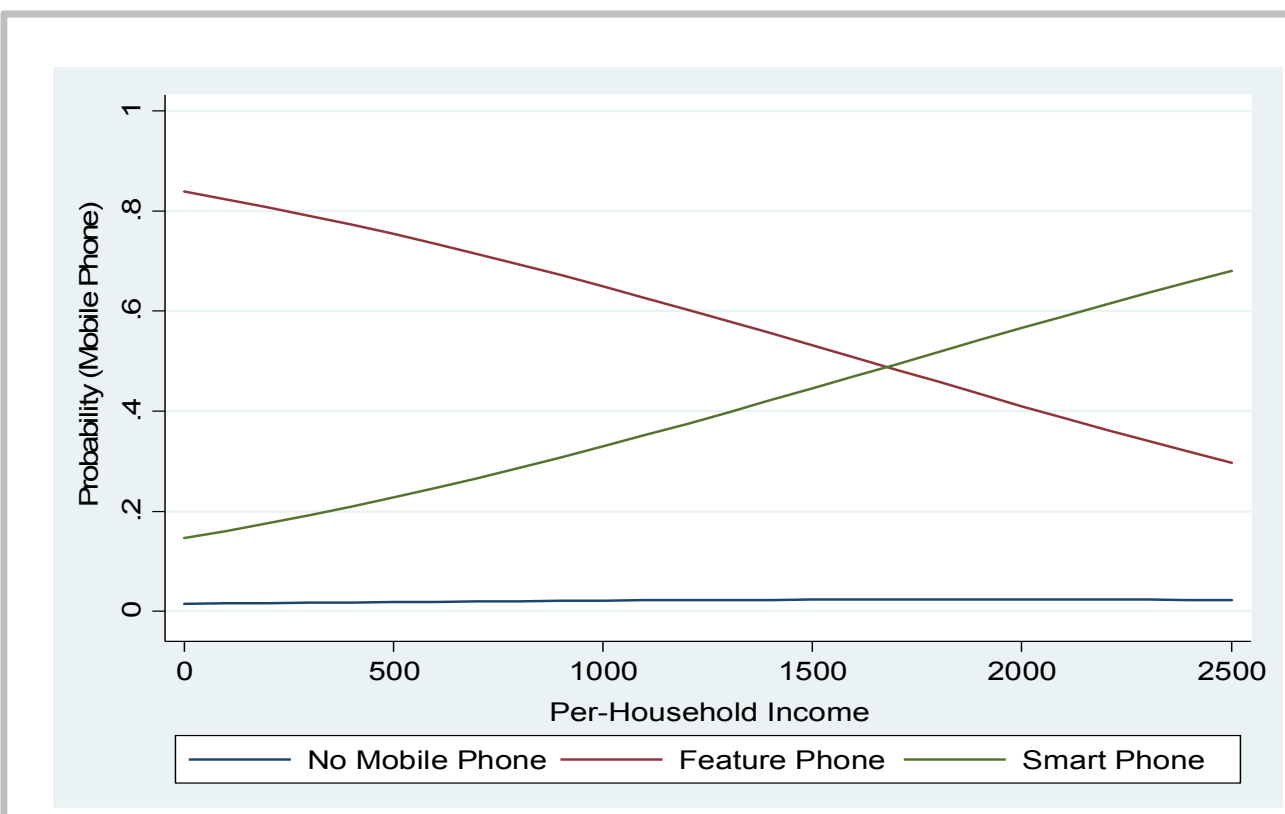

Figure 6a. Prediction probability of Per-Household Income (Source: Authors)

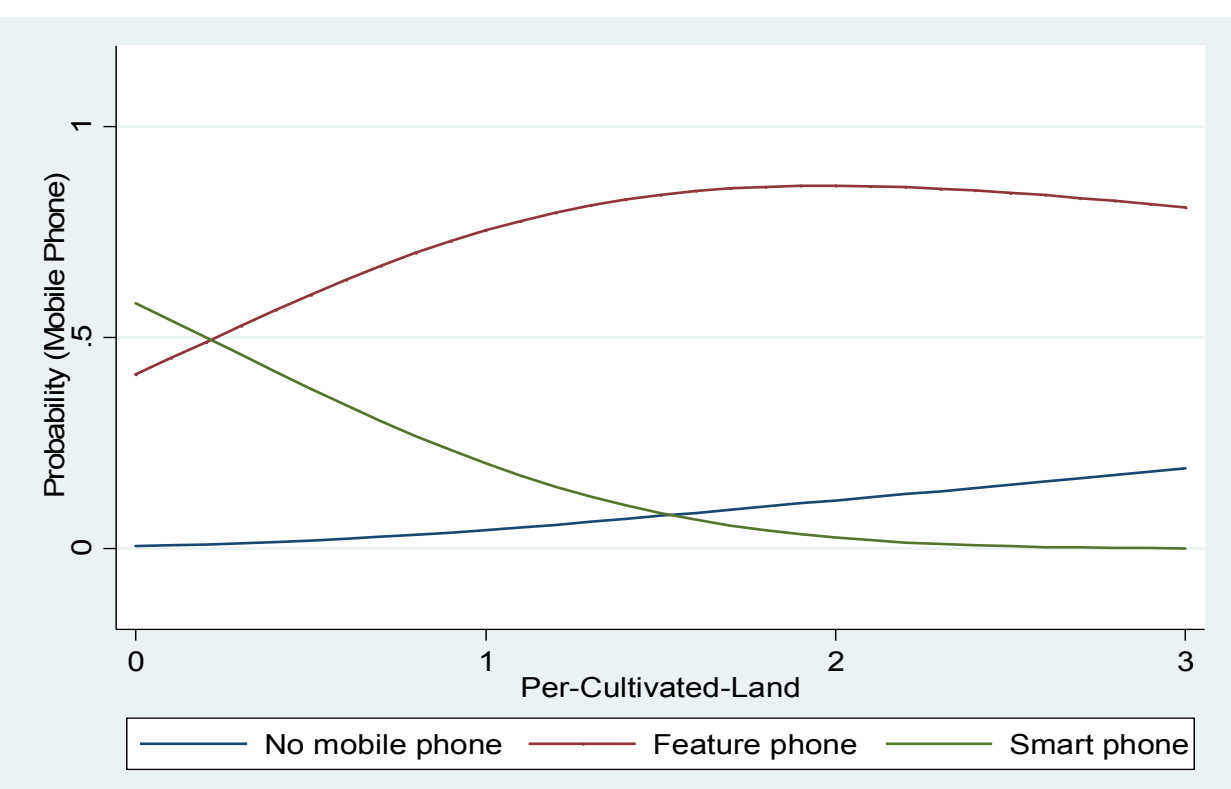

Figure 6b. Prediction probability of Per-Cultivated Land (Source: Authors)

Figure 6. Prediction probability of Smart phone (Source: Authors)

As indicated in estimation result, they switch from feature phone to smart phone with increasing of per-household member's monthly income. This can be confirmed in Figure 6a. Although the estimated parameter of Per-Land of feature phone is not statistically significantly different from 0 , the comparison between feature phone and smart phone is shown in Figure 6b. Increasing land size per household member let them switch from feature phone to mobile phone.

\section{Conclusions}

The objective of this study was to assess the mobile phone diffusion, usage on agriculture based activities and 
factors that determine the choice of mobile phone adopted by household. To achieve this objective, 120 households where surveyed, 7 key informants and 6 focus group discussions were conducted in the selected case study Makueni County in Kenya.

The study depicts that mobile phone is a commonly used asset to access services among households and apart from communication, households can access other services such as agriculture information, access financial services and also others use it to monitor, operate and manage different livelihood activities the households engage in. The access to information, finances and diversification of livelihood are important resources which contribute to mitigating vulnerability of farming household in the face of various risks of their livelihood strategy including extreme weather event and projected climate change in the future, and therefore mobile phone has proven to be a basic platform to increase accessibility to these resources.

Households with a mobile phone are able to receive agricultural information on both crop and livestock, information on daily weather, seasonal and projected long-term precipitation and temperature information, onset and cessation of the rainy season and events which help them to plan their farming activities accordingly. Also, through mobile phone households are able to send and receive money, easily access credit and also can save for their farming activities.

Although we have a wide range of developed mobile phone applications and uses in Kenya targeting farmers to improve their agricultural productivity in changing climate, this study proves that majority of rural households are not aware and lack access to them. Also, the households pointed out that access to the information is expensive, information provided is not enough since some main crops are not included and other indicated a poor network challenge which limits access to these mobile phone services. Therefore, there is a need to create and increase awareness of the rural household on the benefits of these applications on their farming activities. Awareness creation is essential to enlighten households on the available mobile phone uses and applications which provide them with information and financial services to develop their capacity and also improve agricultural productivity.

Furthermore, this study depicts that per-household income, accessibility to credit and per- cultivated land by the household are factors that influence the ability of household on the choice of the mobile phone either a feature phone or smart phone. Most farmers do not have the ability to obtain a smartphone due to the limitation of these resources. Therefore, through these evaluations and identified key challenges encountered by households, this study provides insights to decision makers and service providers to ensures equal distribution of resources and delivery of appropriate services and programs to farming households to improve their agricultural productivity and increase household capacity by accessing information and financial resources through utilization of developed mobile phone services. This study recommends a future study on assessing how a type of mobile phone adopted by household determine the kind of information and financial services accessed.

\section{Acknowledgments}

We appreciate the University of Tokyo, Graduate Program in Sustainability Science-Global Leadership Initiative (GPSS-GLI) for supporting this research especially during fieldwork. Our extended appreciation goes to Lazarus M. (Safaricom), Dr. Emmanuel M. (ADB), Hon. Elizabeth M (Makueni County government), Ministry of Agriculture (Makueni County), Kenya meteorological Department (Makindu Station), Makueni respondents and all the stakeholders involved in this study for their support and cooperation during the data collection period, and their sincere responses to the questionnaires administered.

\section{References}

Aker, J. C., \& Ksoll, C. (2016). Can mobile phones improve agricultural outcomes? Evidence from a randomized experiment in Niger. Food Policy, 60, 44-51. https://doi.org/10.1016/j.foodpol.2015.03.006

Aker, J. C., \& Mbiti, I. M. (2010). Mobile phones and economic development in Africa. The Journal of Economic Perspectives, 24(3), 207-232. https://doi.org/10.1257/jep.24.3.207

Alvarez, R. M., \& Nagler, J. (1994). Correlated Disturbances in Discrete Choice Models: a Comparison of Multinomial Probit Models and Logit Models. Working Papers 914, California Institute of Technology, Division of the Humanities and Social Sciences.

Bukania, Z. N., Mwangi, M., Karanja, R. M., Mutisya, R., Kombe, Y., Kaduka, L. U., \& Johns, T. (2014). Food insecurity and not dietary diversity is a predictor of nutrition status in children within semiarid agro-ecological zones in eastern Kenya. Journal of nutrition and metabolism. https://doi.org/10.1155/2014/907153 
Cameron, A. C., \& Trivedi, P. K. (2005). Micro econometrics: Methods and Applications. New York: Cambridge University Press. https://doi.org/10.1017/CBO9780511811241

Cameron, A. C., \& Trivedi, P. K. (2009). Micro econometrics with STATA. College Station, TX: Stata Corp LP.

Crandall, A. (2012). Kenyan farmers' use of cell phones: Calling preferred over SMS. M4D, 119-129.

GSMA - GSM World. (2018). The m-Farmer Initiative. Retrieved October, 2018, from http://www.gsmworld.com/our-work/mobile_planet/development_fund/mfarmer_initiative_fund.htm

International Telecommunication Union (ITU). (2017). ICT Statistics Database. Retrieved July, 2017, from http://www.itu.int/ict/statistics

Lawal-Adebowale, O. A., \& Akeredolu-Ale, B. I. (2010). Agricultural workers' perception of information and communication technology usage for agricultural development in Southwest Nigeria. Journal of Social Development in Africa, 25(2), 147.

M-Farm. (2018). Retrieved October, 2018, from http://www.mfarm.co.ke

Mittal, S., \& Mehar, M. (2012). How mobile phones contribute to growth of small farmers? Evidence from India. Quarterly Journal of International Agriculture, 51(3), 227.

M-Pesa. (2018). Retrieved October, 2018, from https://www.safaricom.co.ke/personal/m-pesa

M-Shwari. (2018). Retrieved October, 2018, from https://cbagroup.com/m-shwari/what-is-m-shwari/

Murray, C. E. (2009). Diffusion of Innovation Theory: A Bridge for the Research- Practice Gap in Counselling. Journal of Counselling \& Development, 87. https://doi.org/10.1002/j.1556-6678.2009.tb00556.x

Qiang, C. Z., Kuek, S. C., Dymond, A., Esselaar, S., \& Unit, I. S. (2011). Mobile applications for agriculture and rural development. World Bank, Washington, DC.

Rhodes, C. J. (2016). The 2015 Paris climate change conference: COP21. Science progress, 99(1), 97-104. https://doi.org/10.3184/003685016X14528569315192

Roaf, S., Crichton, D., \& Nicol, F. (2009). Adapting buildings and cities for climate change: a 21st century survival guide. Routledge.

Rogers, E. M. (2003). Elements of diffusion. Diffusion of innovations, 5(1.38).

\section{Copyrights}

Copyright for this article is retained by the author(s), with first publication rights granted to the journal.

This is an open-access article distributed under the terms and conditions of the Creative Commons Attribution license (http://creativecommons.org/licenses/by/4.0/). 